\title{
Title of Manuscript: Two Novel Glycosidic Triterpene Alkaloids from the Stem Barks of Machilus yaoshansis
}

Author list: Ming-Tao Liu, Sheng Lin, Ying-Hong Wang, Wen-Yi He, Shuai Li, Su-Juan Wang, Yong-Chun Yang, Jian-Gong Shi*

\section{Supporting Information Available}

(Continuation) 


\section{The List of Contents}

\begin{tabular}{|c|c|c|}
\hline no. & Content & Page \\
\hline 1 & The Positive (up) and Negative (low) ESIMS Spectrum of Machilaminoside A (1) & S3 \\
\hline 2 & The HR-ESIMS Spectrum of Machilaminoside A (1) & S4 \\
\hline 3 & The IR Positive Spectral Data of Machilaminoside A (1) & S5 \\
\hline 4 & The ${ }^{1} \mathrm{H}$ NMR Spectrum of Machilaminoside A (1) in DMSO- $d_{6}$ & S6 \\
\hline 5 & The ${ }^{1} \mathrm{H}$ NMR Spectrum of Machilaminoside A (1) in DMSO- $d_{6}+\mathrm{D}_{2} \mathrm{O}$ & S7 \\
\hline 6 & The ${ }^{13} \mathrm{C}$ NMR Spectrum of Machilaminoside A (1) in DMSO- $d_{6}$ & S8 \\
\hline 7 & The DEPT Spectrum of Machilaminoside A (1) in DMSO- $d_{6}$ & S9 \\
\hline 8 & The HMQC Spectrum of Machilaminoside A (1) in DMSO- $d_{6}$ & S10 \\
\hline 9 & The HMBC Spectrum of Machilaminoside A (1) in DMSO- $d_{6}$ & S11 \\
\hline 10 & The Regional Enlarged HMBC Spectrum 1 of Machilaminoside A (1) in DMSO- $d_{6}$ & $\mathrm{~S} 12$ \\
\hline 11 & The Regional Enlarged HMBC Spectrum 2 of Machilaminoside A (1) in DMSO- $d_{6}$ & S13 \\
\hline 12 & The Regional Enlarged HMBC Spectrum 3 of Machilaminoside A (1) in DMSO- $d_{6}$ & S14 \\
\hline 13 & The Regional Enlarged HMBC Spectrum 4 of Machilaminoside A $(\mathbf{1})$ in DMSO- $d_{6}$ & S15 \\
\hline 14 & The NOESY Spectrum of Machilaminoside A (1) in DMSO- $d_{6}$ & S16 \\
\hline 15 & The NOE Difference Spectrum of Machilaminoside A (1) in DMSO- $d_{6}+\mathrm{D}_{2} \mathrm{O}$ & S17 \\
\hline 16 & The CD Spectrum of Machilaminoside A (1) in $\mathrm{MeOH}$ & S18 \\
\hline 17 & The Positive ESIMS Spectrum of Machilaminoside B (2) & S19 \\
\hline 18 & The Positive HR-ESIMS Spectral Data of Machilaminoside B (2) & S20 \\
\hline 19 & The IR Spectrum of Machilaminoside B (2) in DMSO- $d_{6}$ & S21 \\
\hline 20 & The ${ }^{1} \mathrm{H}$ NMR Spectrum of Machilaminoside B (2) in DMSO- $d_{6}$ & S22 \\
\hline 21 & The ${ }^{1} \mathrm{H}$ NMR Spectrum of Machilaminoside B (2) in DMSO- $d_{6}+\mathrm{D}_{2} \mathrm{O}$ & S23 \\
\hline 22 & The ${ }^{13} \mathrm{C}$ NMR Spectrum of Machilaminoside B (2) in DMSO- $d_{6}$ & S24 \\
\hline 23 & The DEPT Spectrum of Machilaminoside B (2) in DMSO- $d_{6}$ & $\mathrm{~S} 25$ \\
\hline 24 & The ${ }^{1} \mathrm{H}^{-1} \mathrm{H}$ COSY Spectrum Machilaminoside B (2) in DMSO- $d_{6}$ & S26 \\
\hline 25 & The HMQC Spectrum of Machilaminoside B (2) in DMSO- $d_{6}$ & S27 \\
\hline 26 & The HMBC Spectrum of Machilaminoside B (2) in DMSO- $d_{6}+\mathrm{D}_{2} \mathrm{O}$ & S28 \\
\hline 27 & The Regional Enlarged HMBC Spectrum 1 of Machilaminoside B (2) in DMSO- $d_{6}+\mathrm{D}_{2} \mathrm{O}$ & S29 \\
\hline 28 & The Regional Enlarged HMBC Spectrum 2 of Machilaminoside B (2) in DMSO- $d_{6}+\mathrm{D}_{2} \mathrm{O}$ & $\mathrm{S} 30$ \\
\hline 29 & The Regional Enlarged HMBC Spectrum 3of Machilaminoside B (2) in DMSO- $d_{6}+\mathrm{D}_{2} \mathrm{O}$ & S31 \\
\hline 30 & The Regional Enlarged HMBC Spectrum 4 of Machilaminoside B (2) in DMSO- $d_{6}+\mathrm{D}_{2} \mathrm{O}$ & $\mathrm{S} 32$ \\
\hline 31 & The NOESY Spectrum of Machilaminoside B (2) in DMSO- $d_{6}$ & S33 \\
\hline 32 & The CD Spectrum of Machilaminoside B (2) & S34 \\
\hline
\end{tabular}




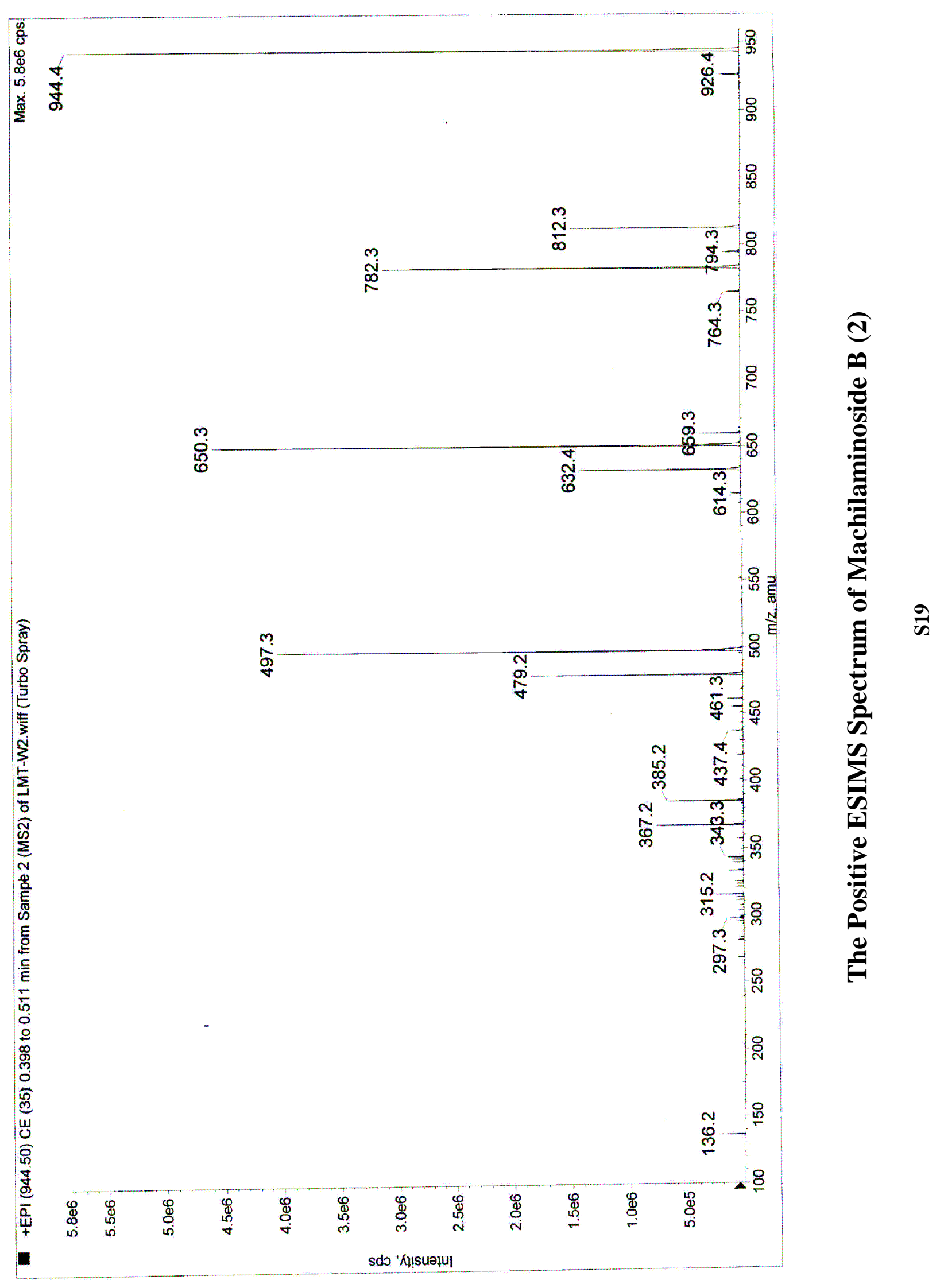



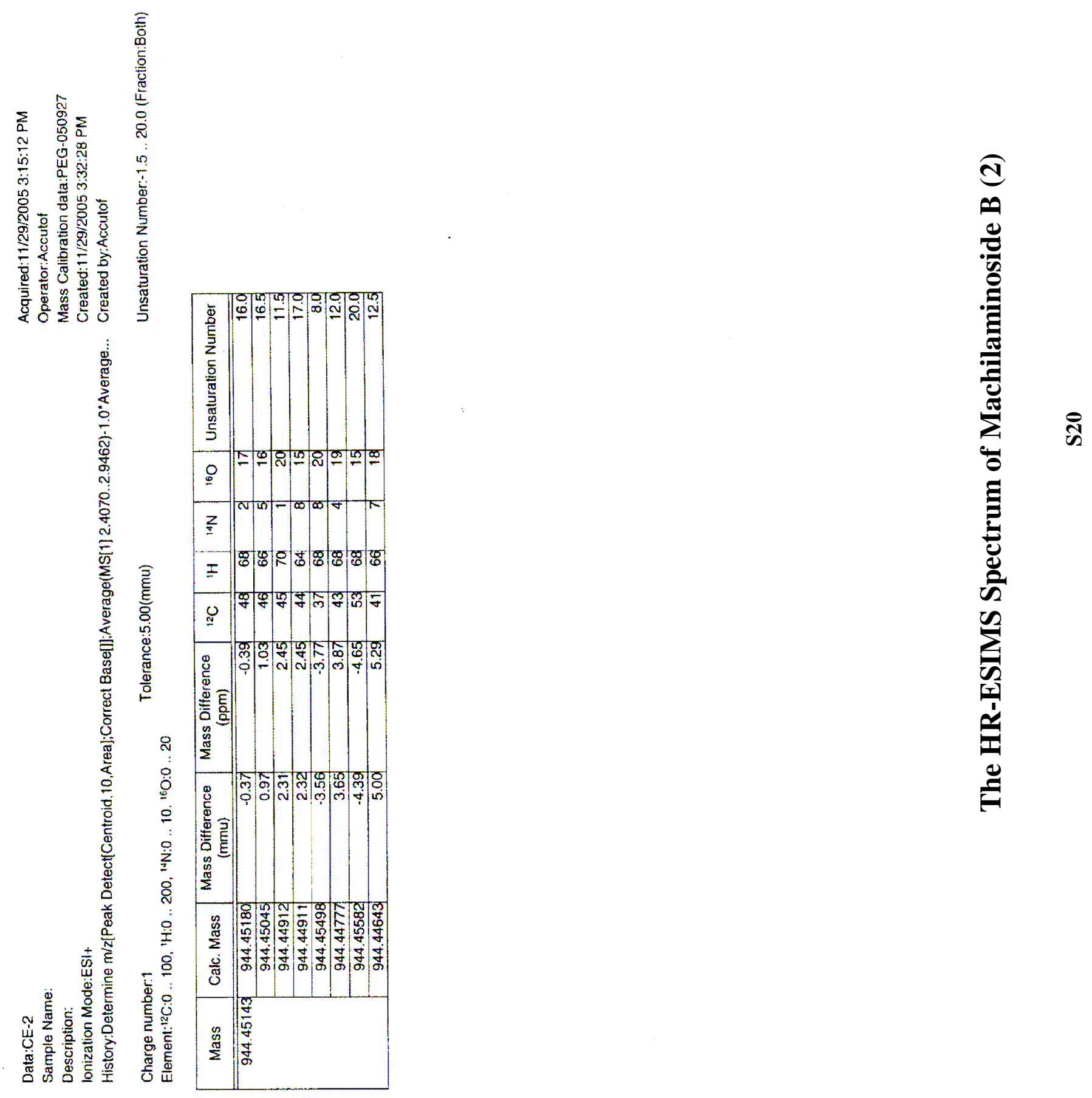


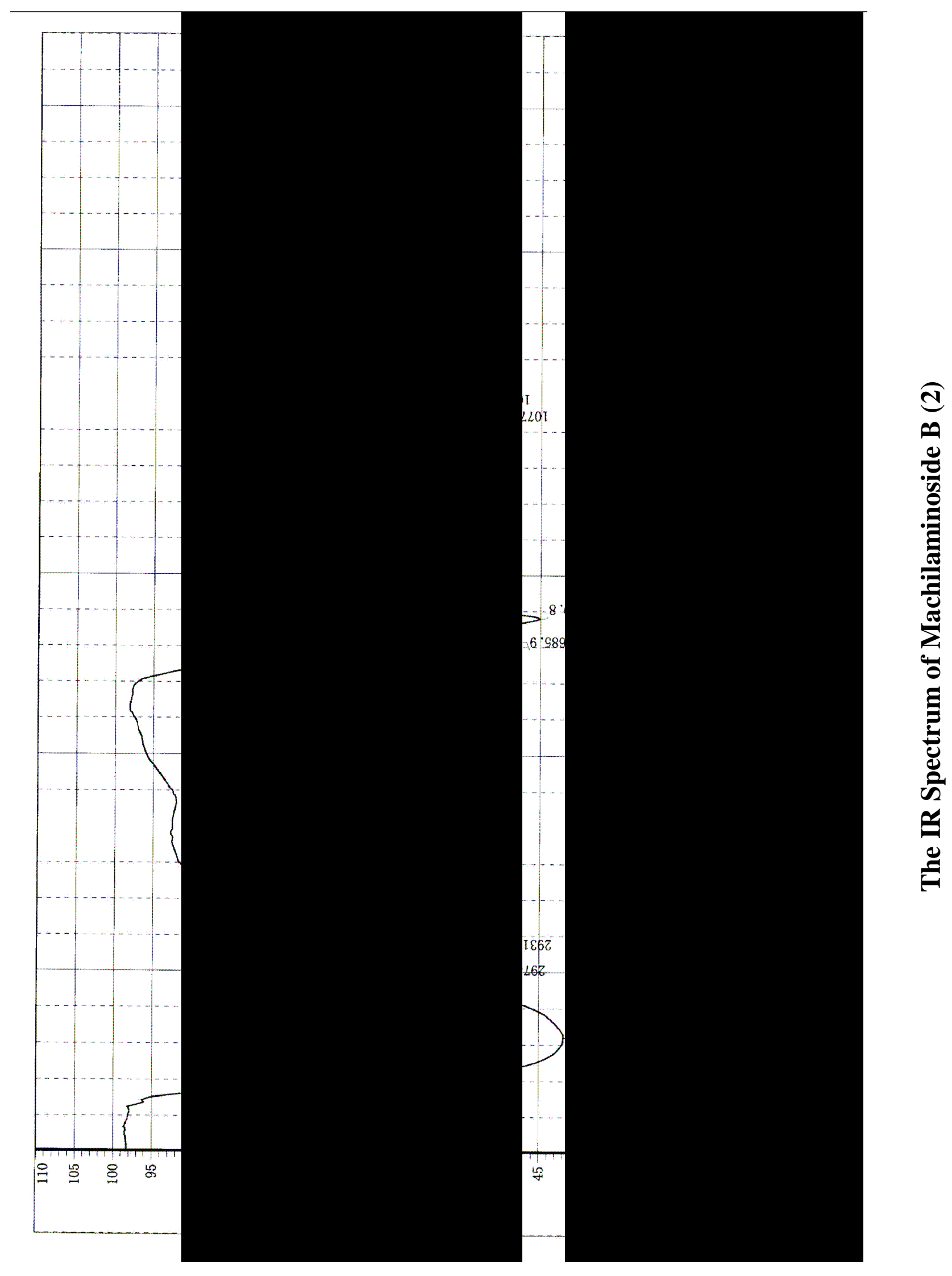




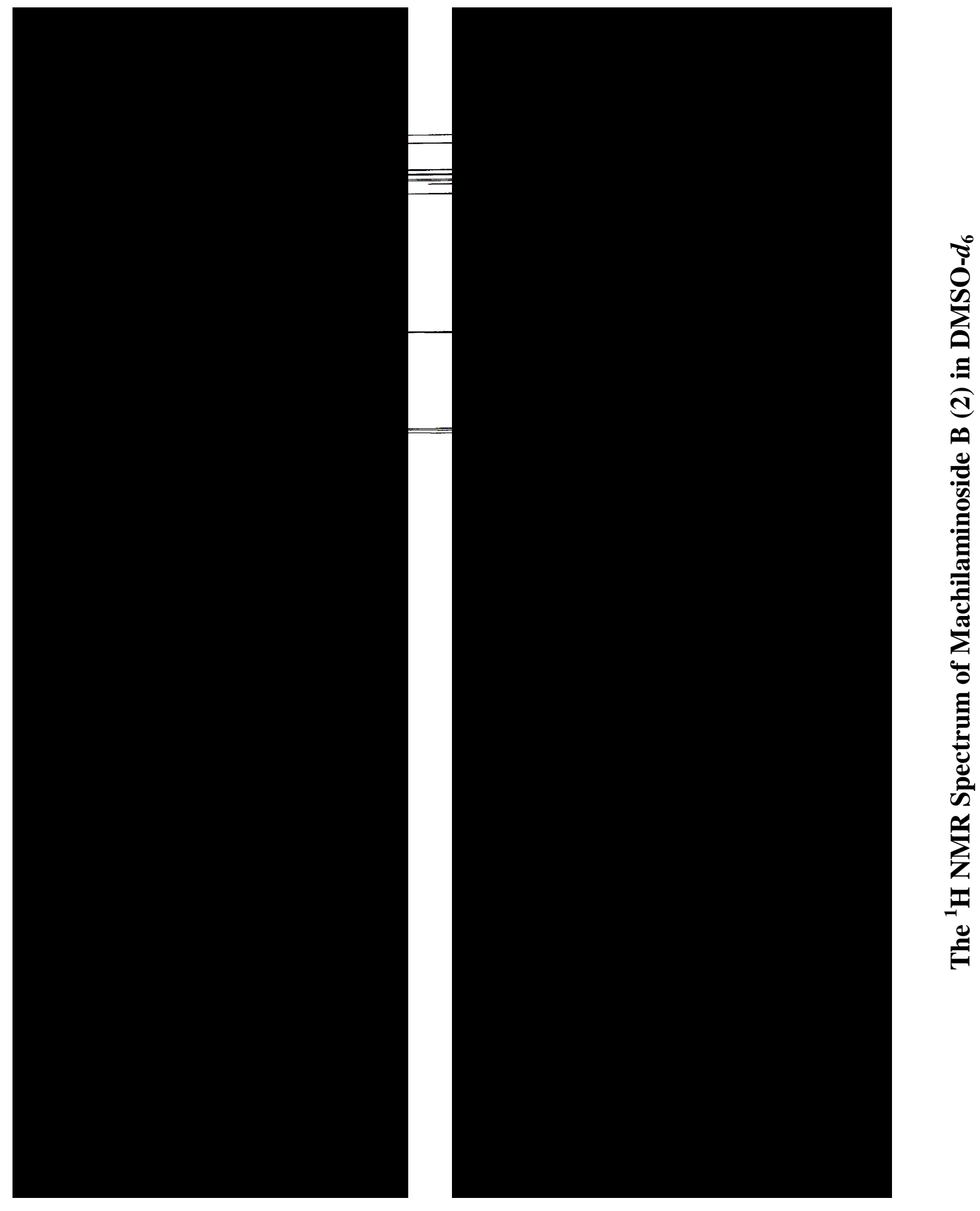




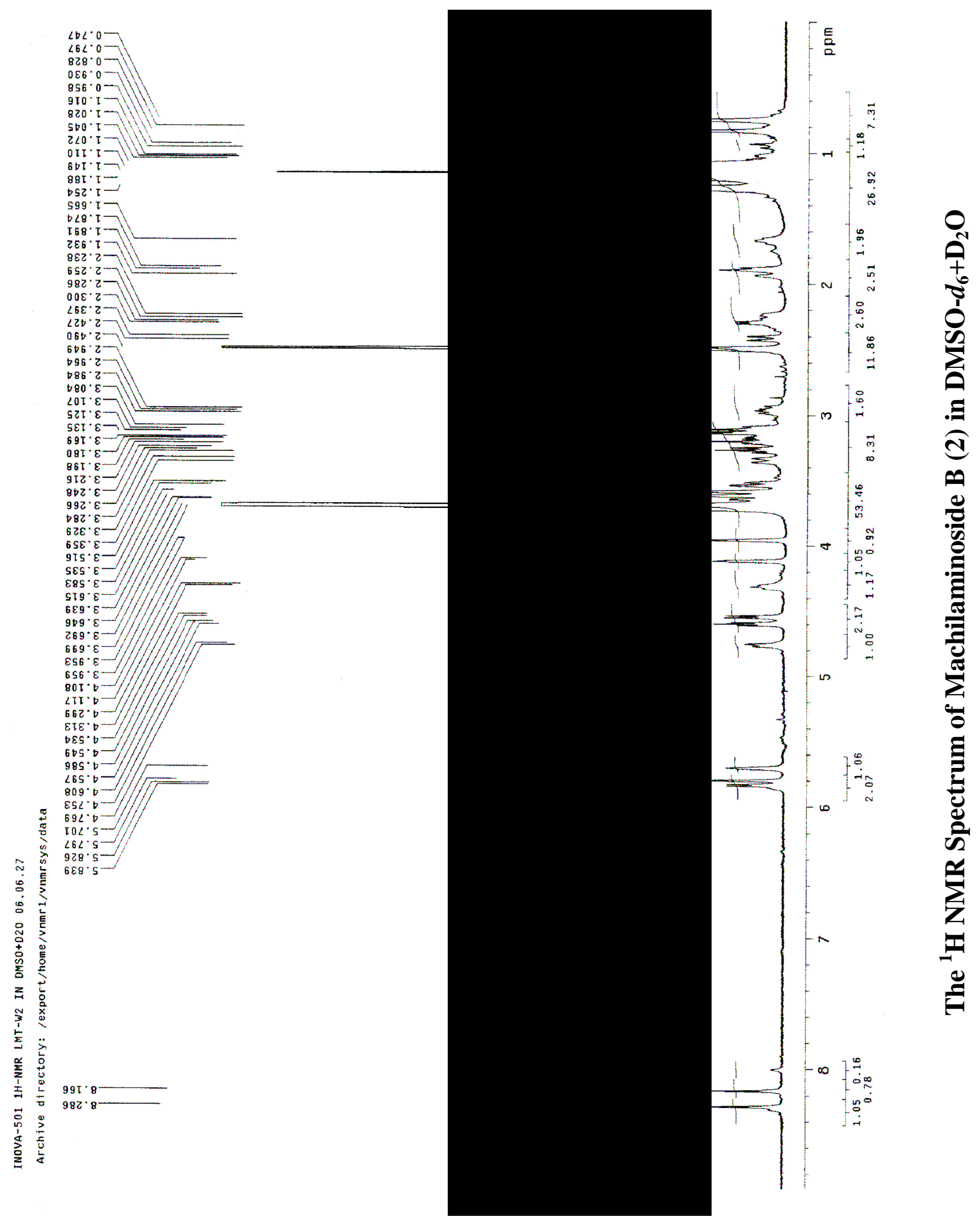




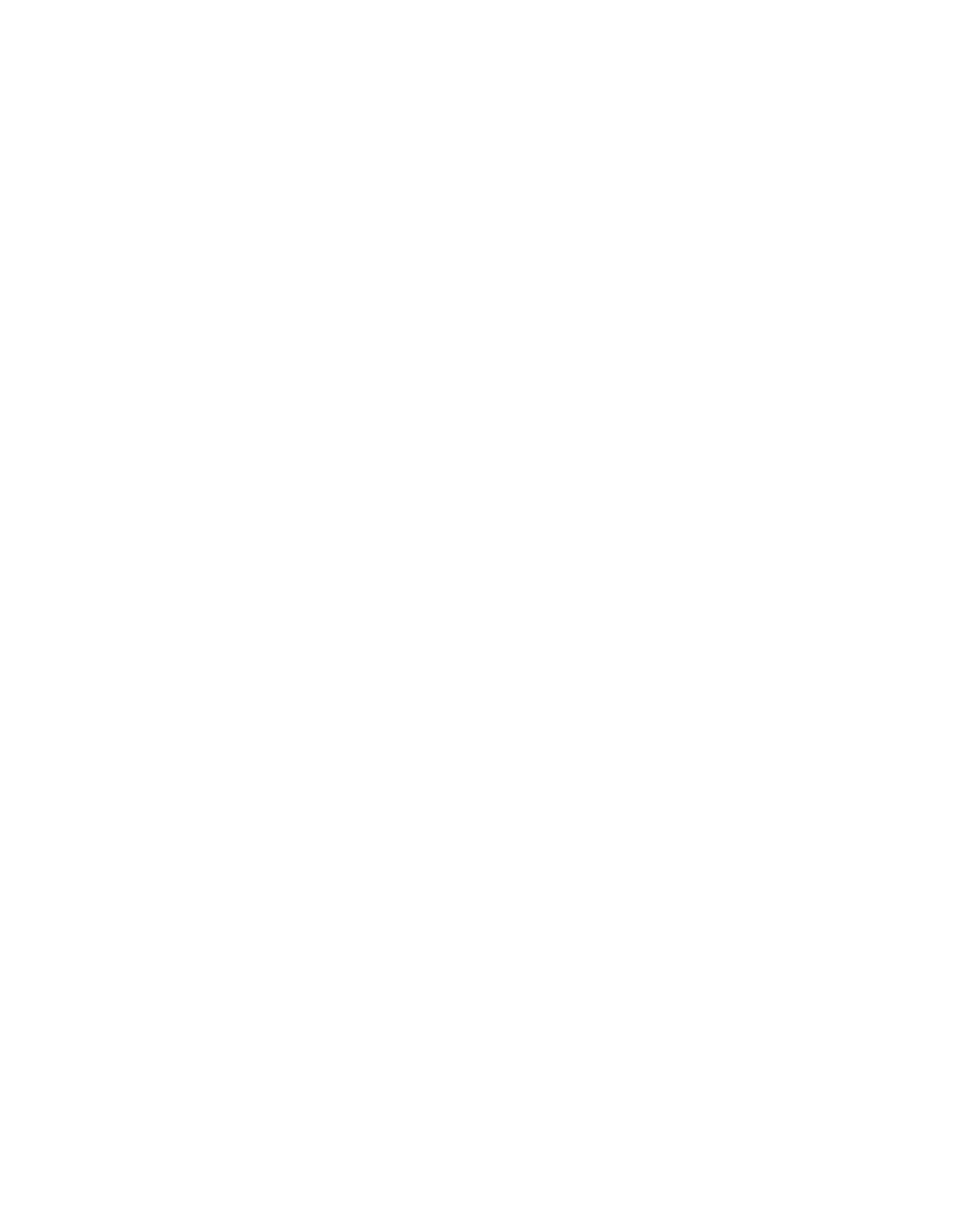

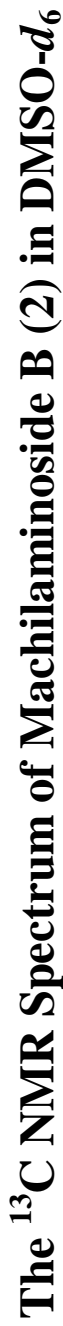



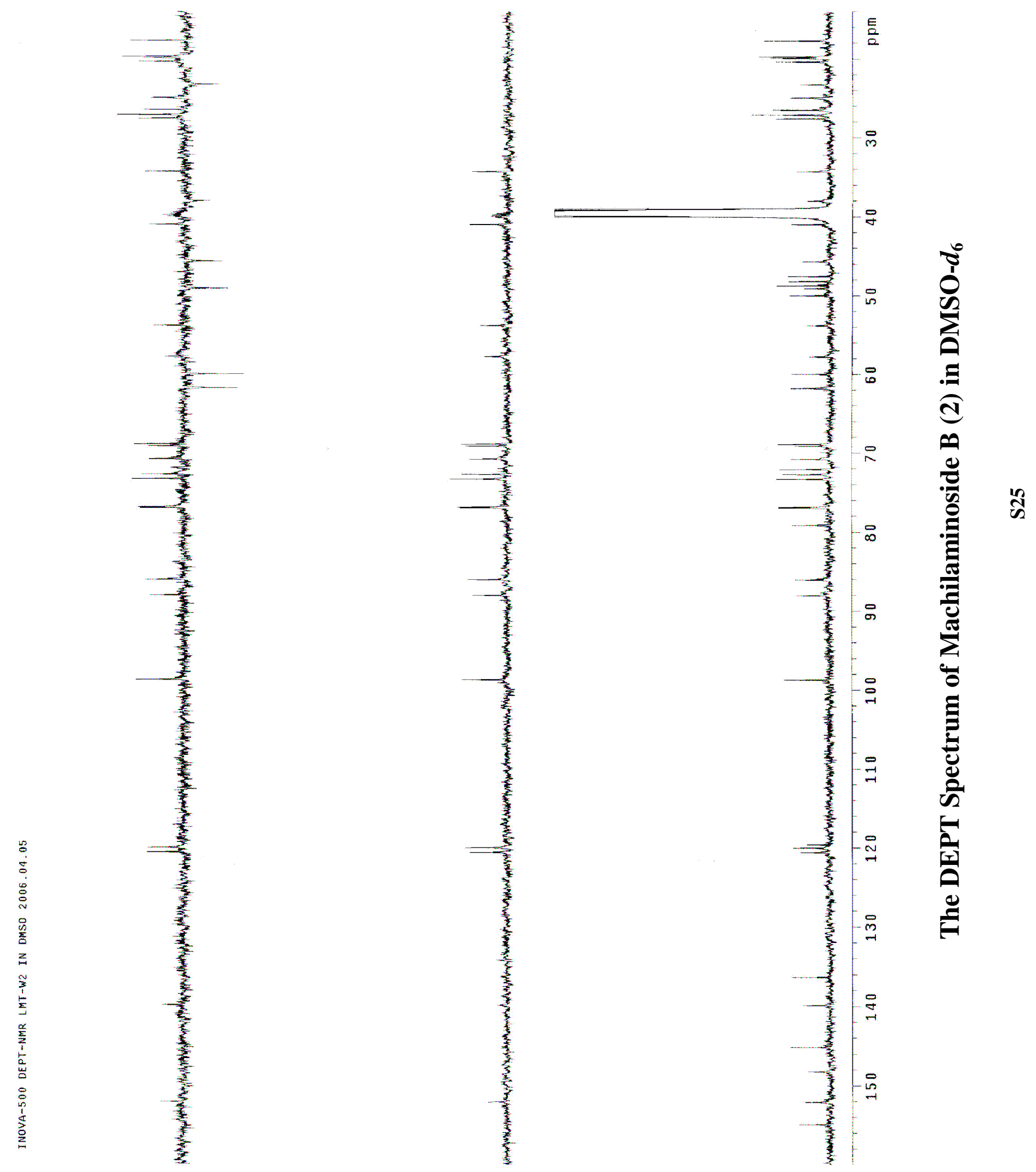


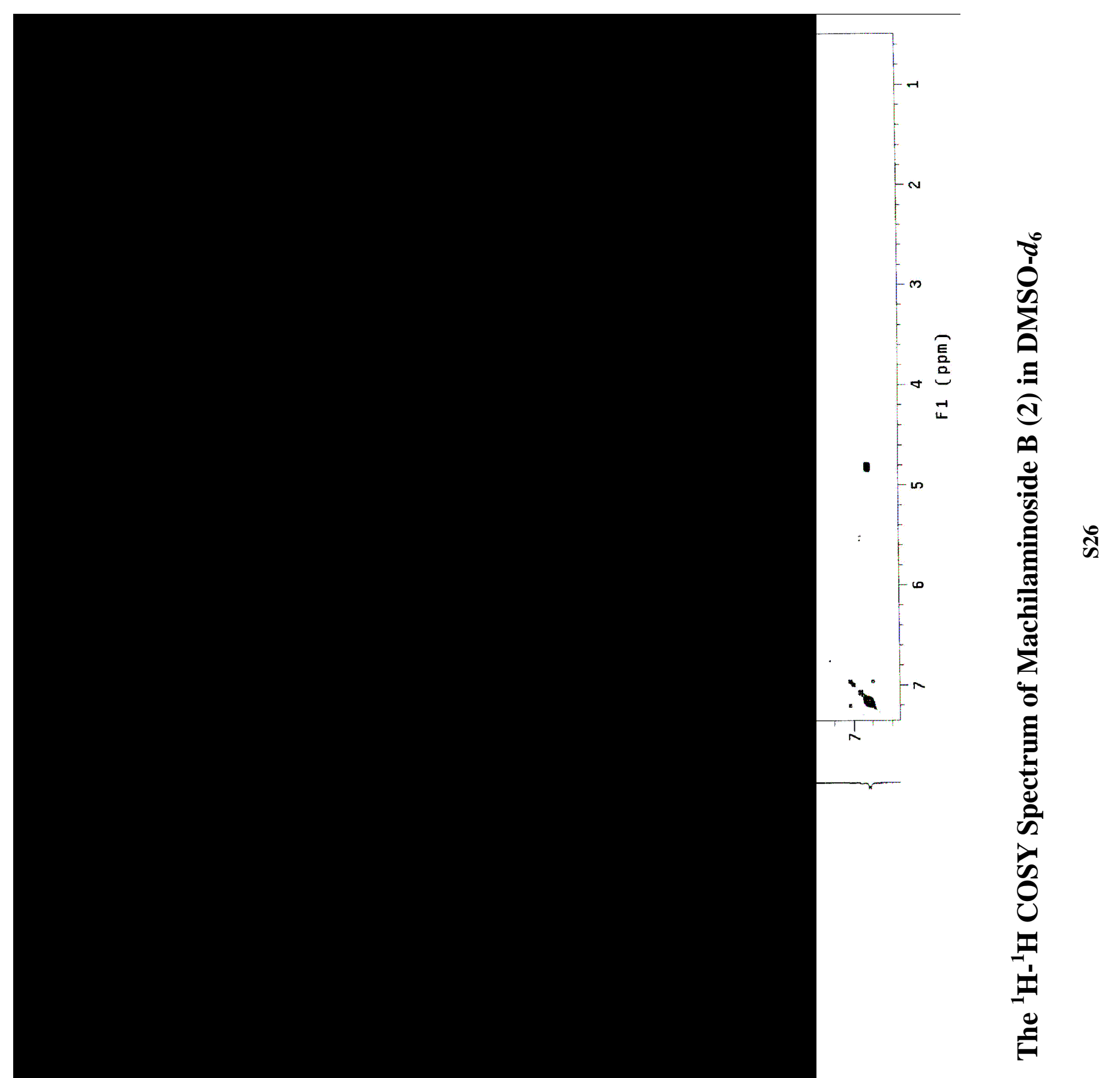




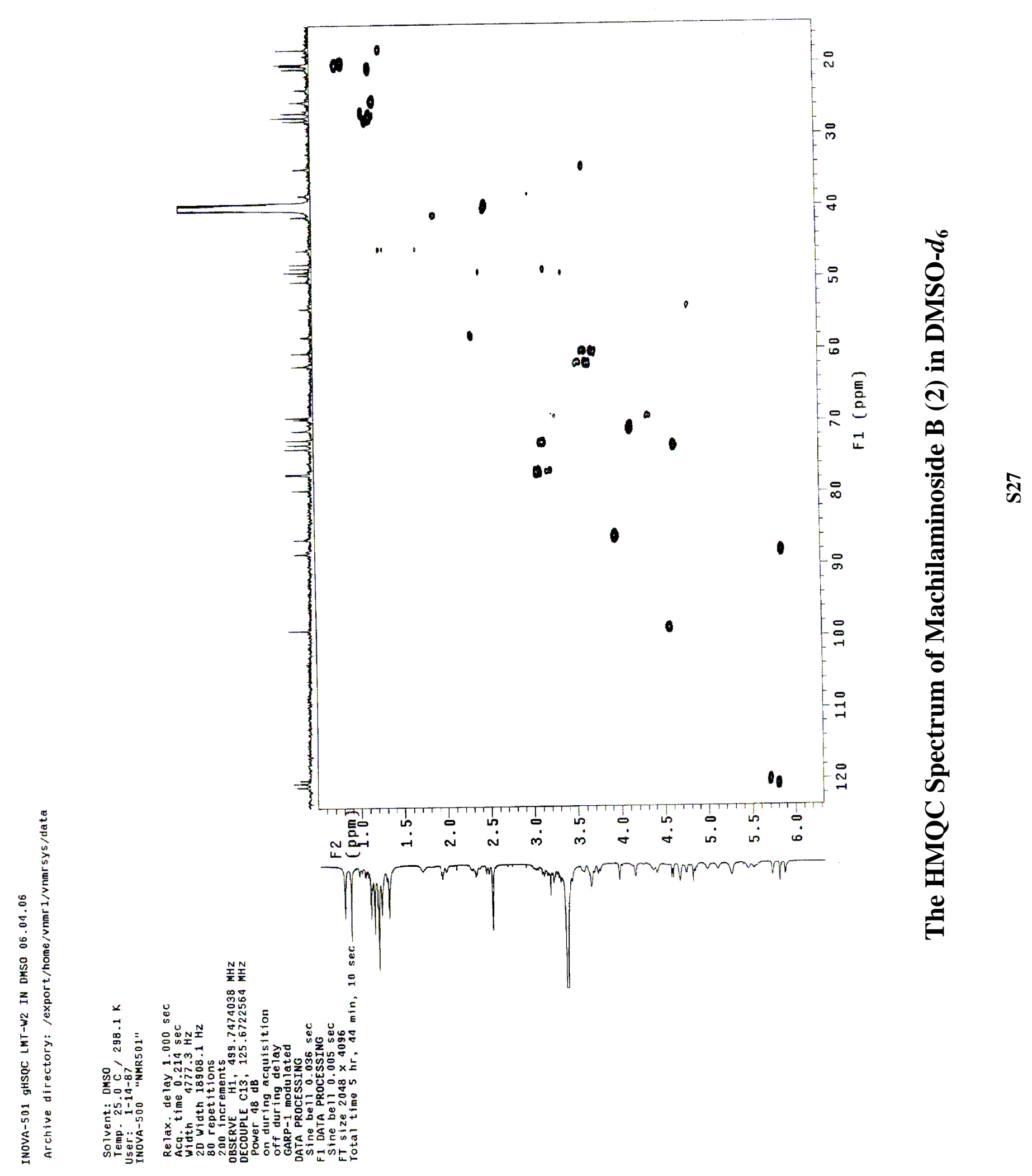




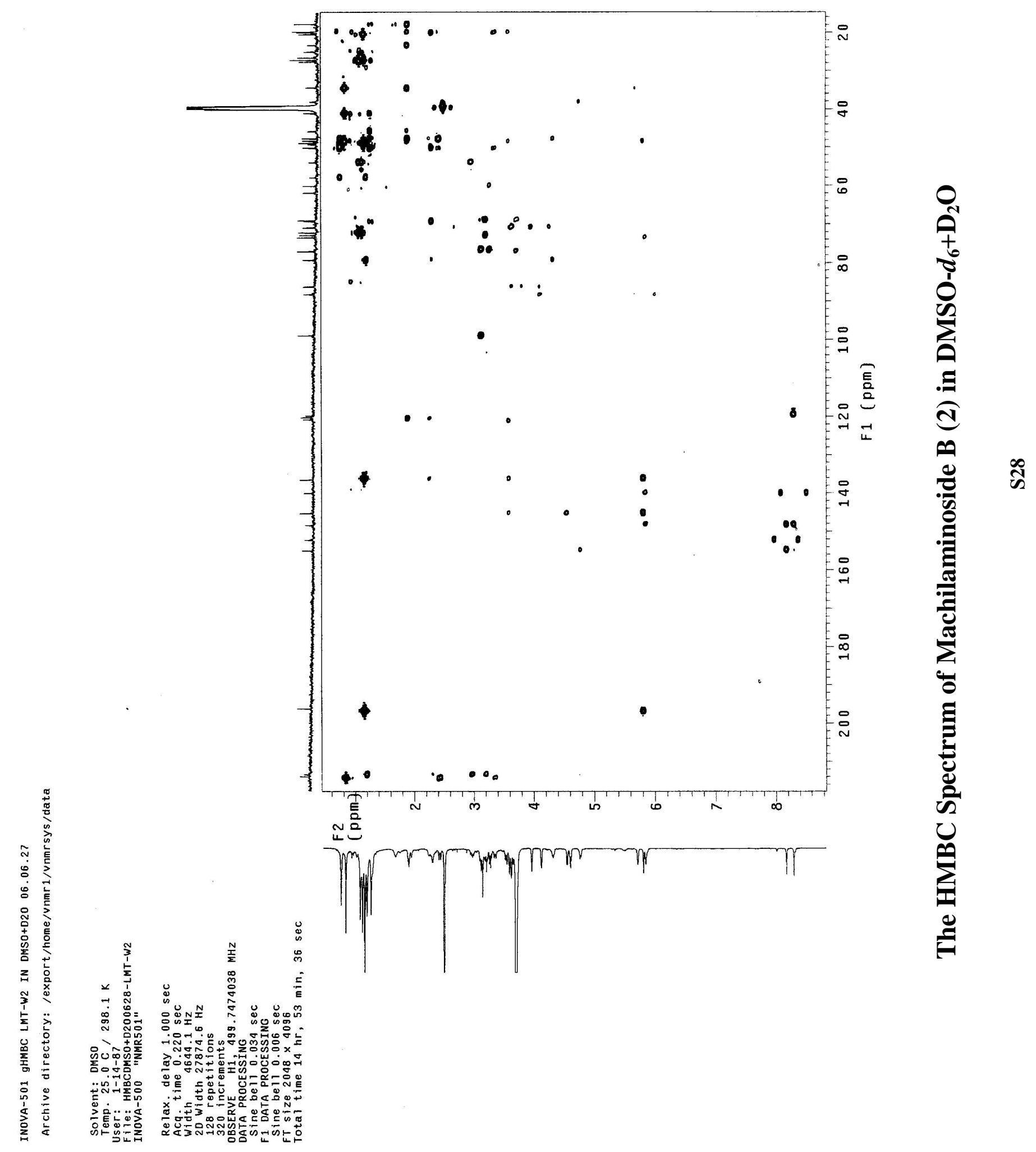




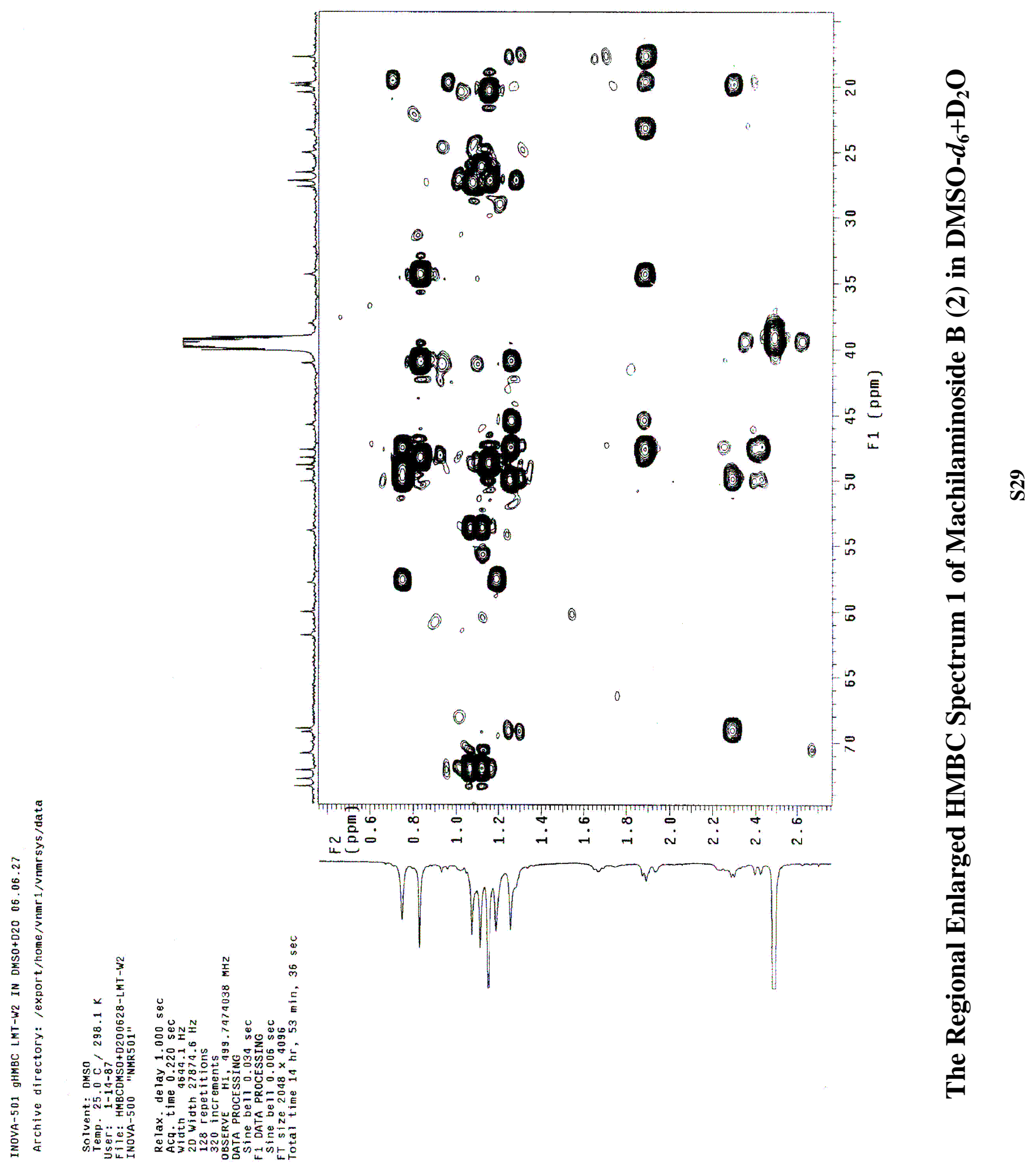




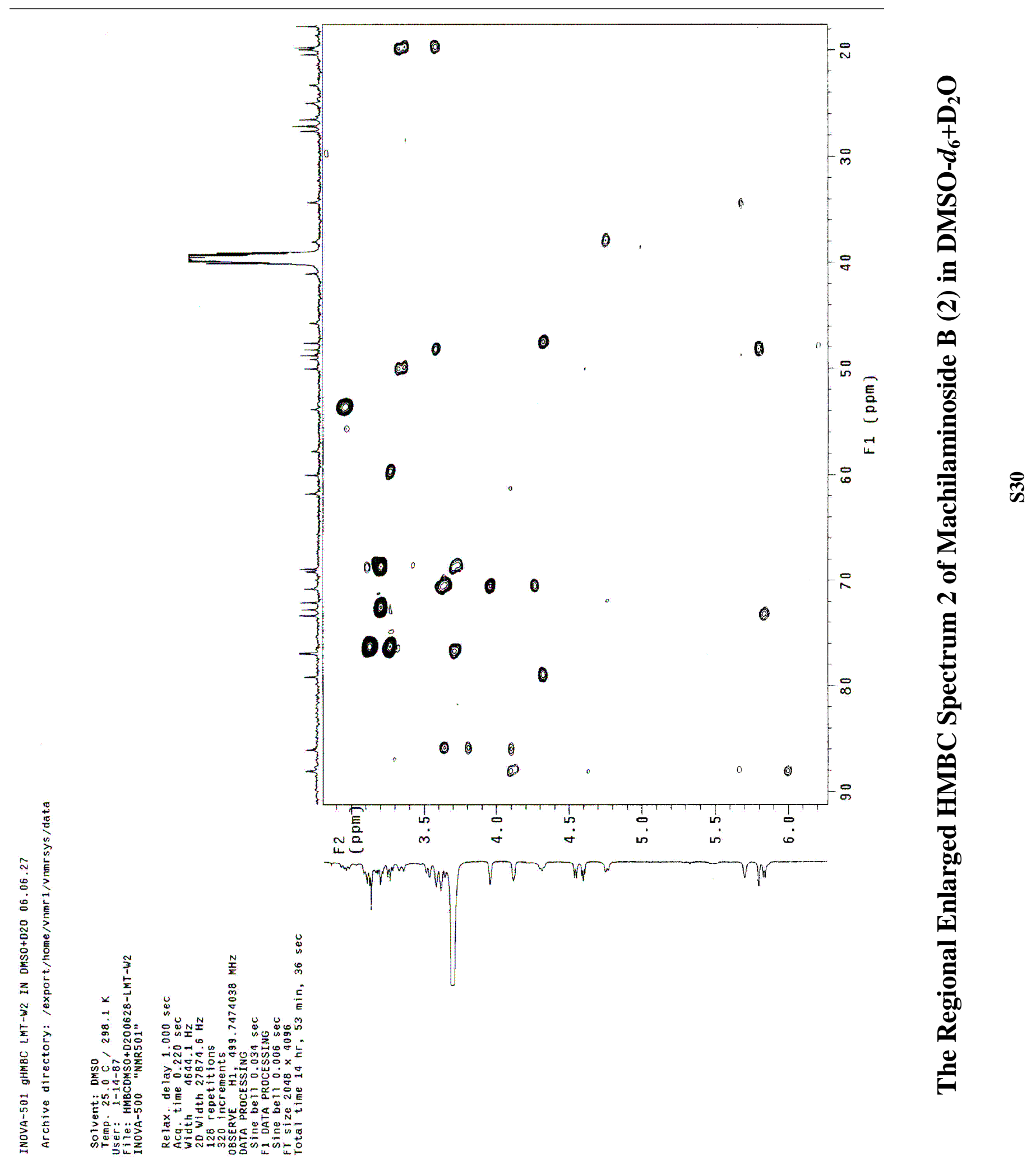




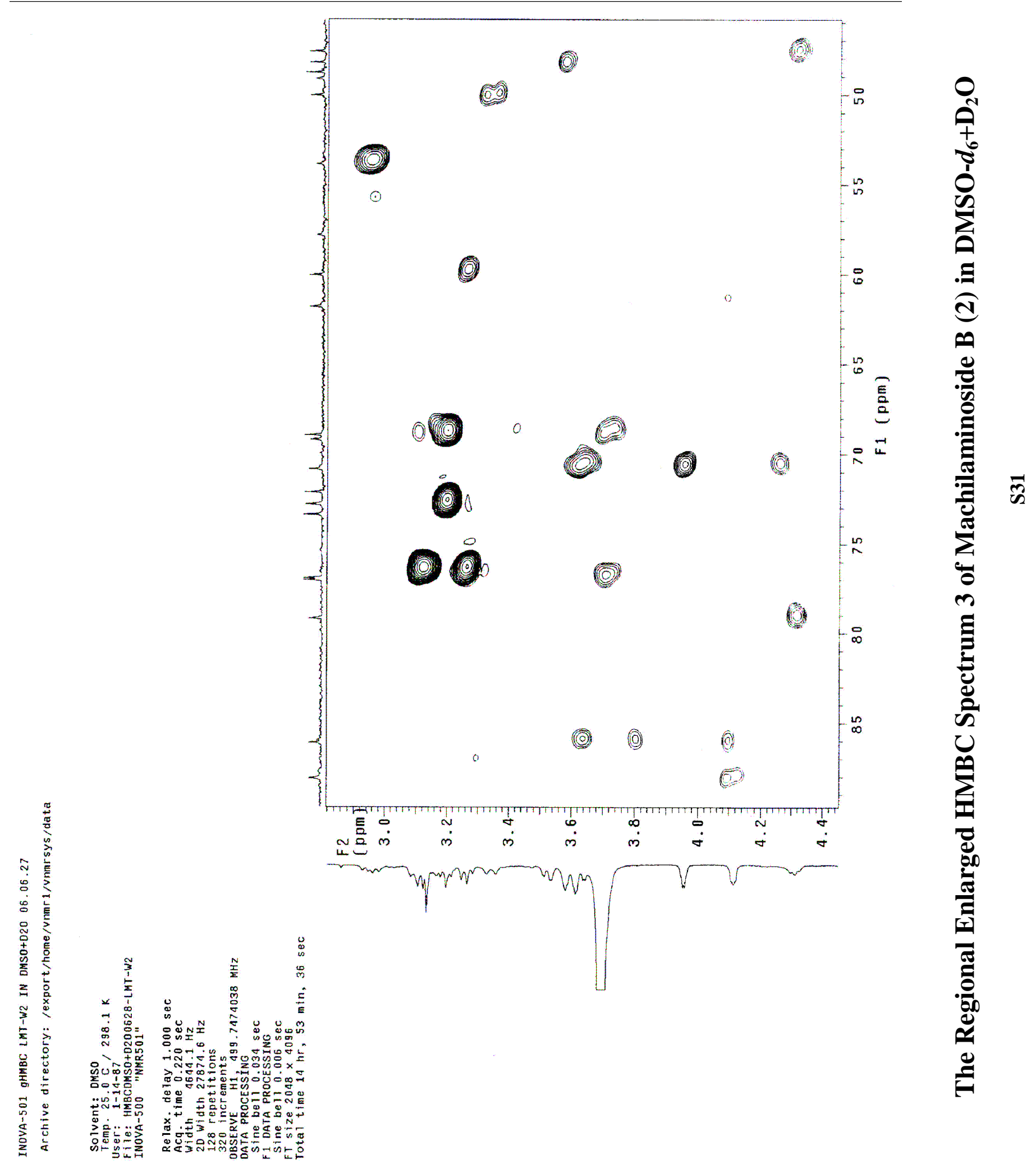




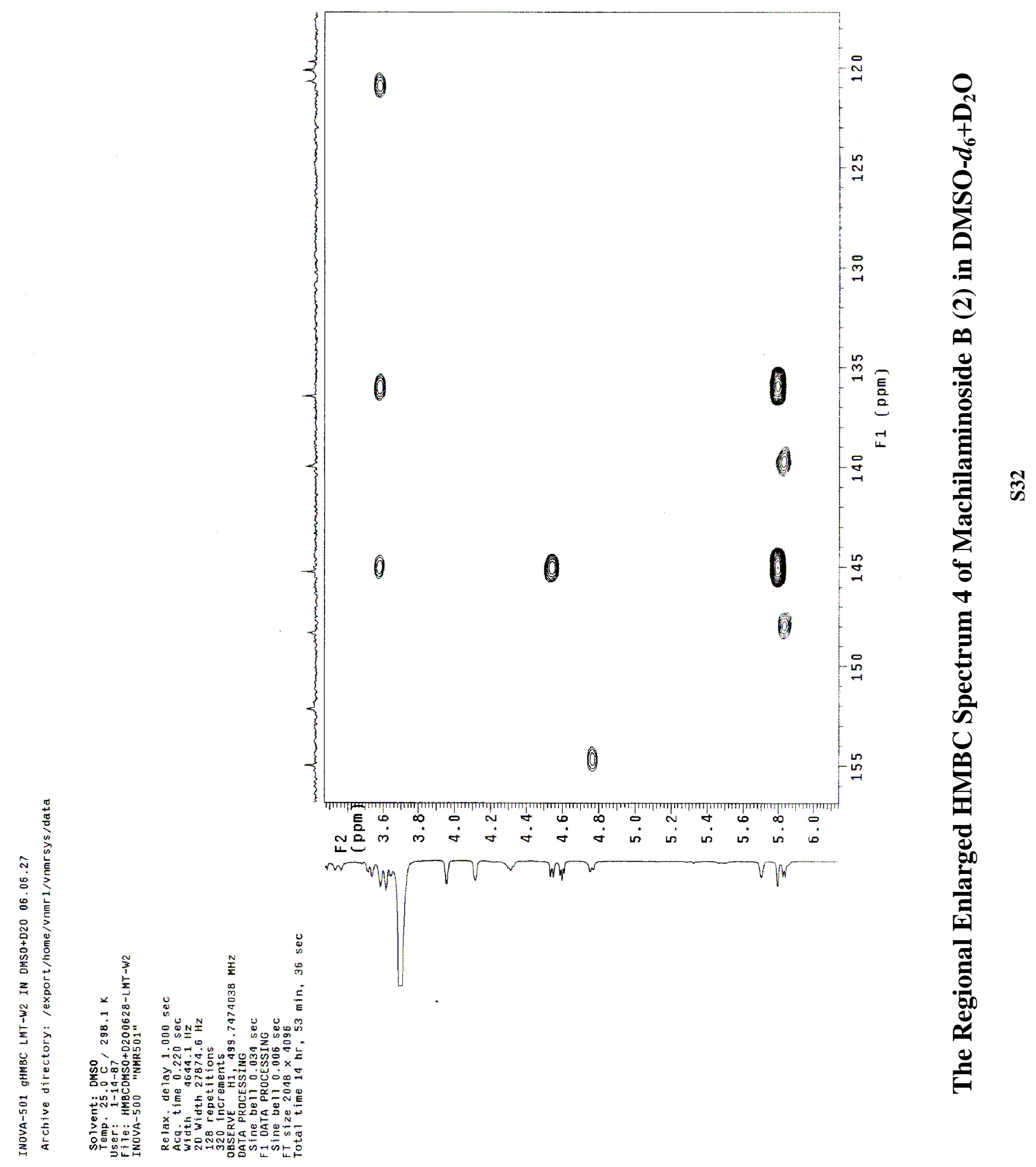




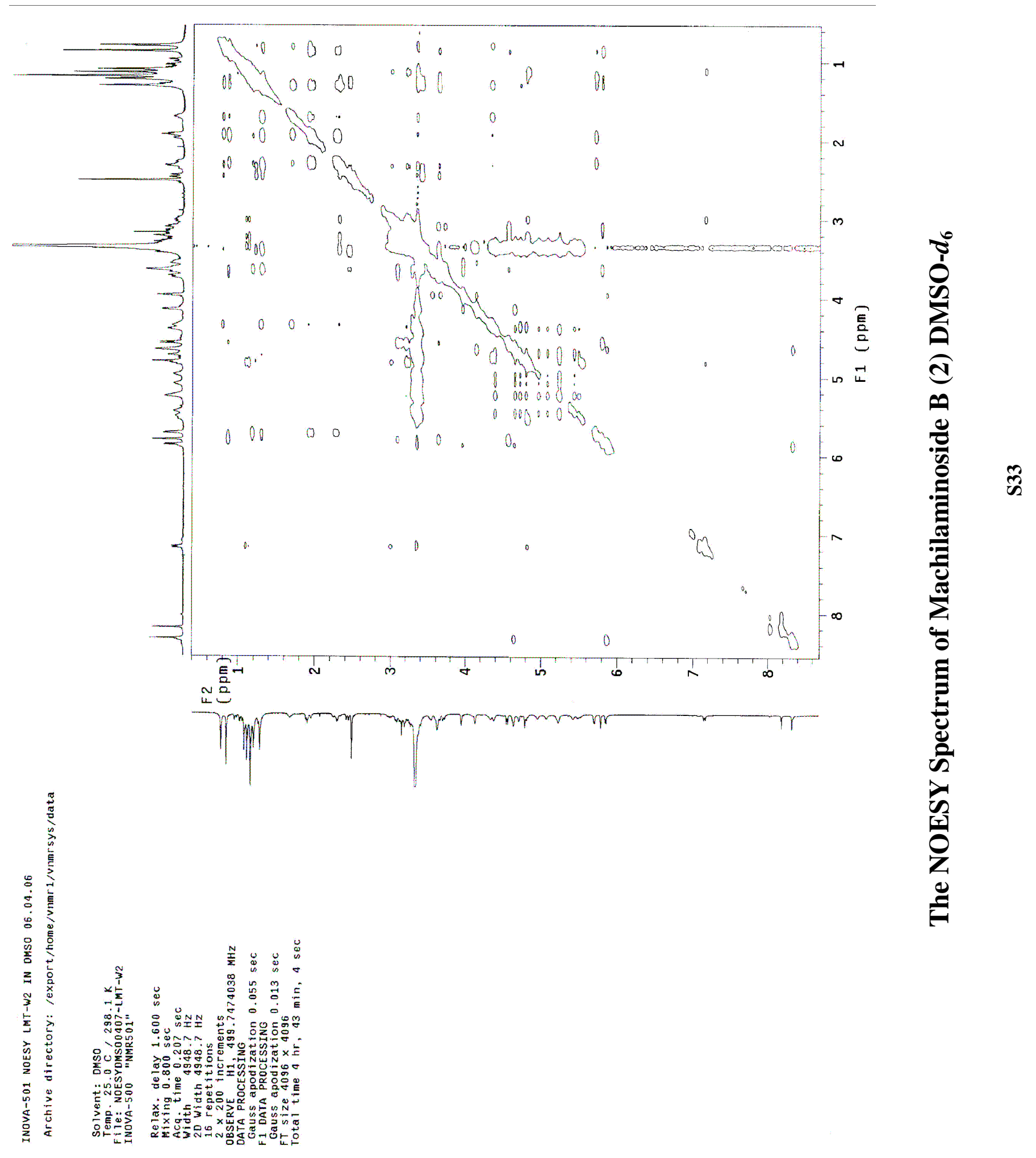



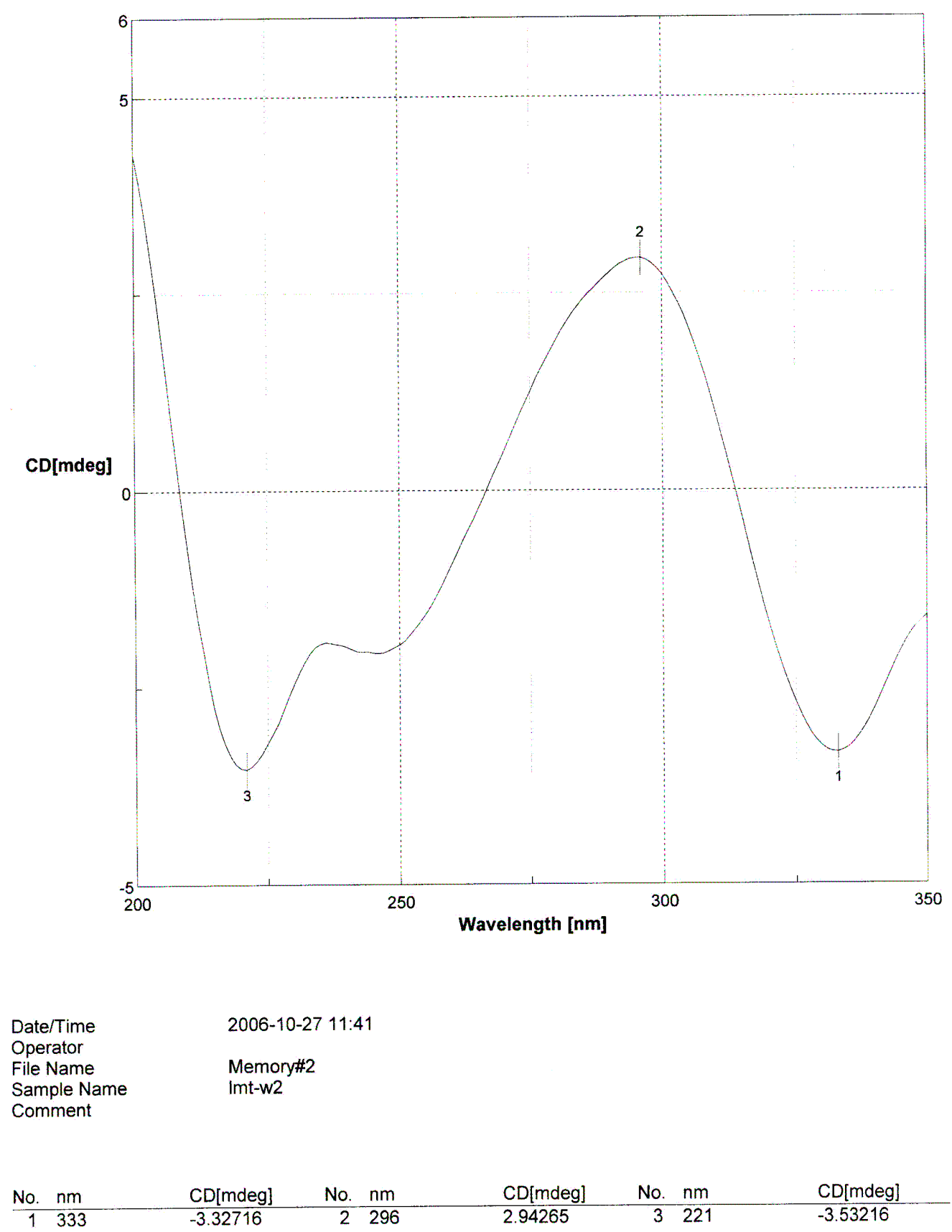

The CD Spectrum of Machilaminoside B (2) in MeOH 